\title{
Workplace Violence Among Health Care Professionals in Public and Private Health Facilities in Bangladesh
}

\begin{abstract}
Md. Shahjalal ${ }^{1,2 *}$, Jeff Gow ${ }^{3,4}$, Mohammad M. Alam ${ }^{2,5}$, Tanvir Ahmed ${ }^{1,2}$, Samar K. Chakma ${ }^{1,2}$, Faroque M. Mohsin ${ }^{1,2}$, Mohammad D. H. Hawlader ${ }^{1}$ and Rashidul A. Mahumud ${ }^{6,7}$

${ }^{1}$ Department of Public Health, School of Health and Life Sciences, North South University, Dhaka, Bangladesh, ${ }^{2}$ Research Rats, Dhaka, Bangladesh, ${ }^{3}$ School of Business and Centre for Health Research, University of Southern Queensland, Toowoomba, QLD, Australia, ${ }^{4}$ School of Accounting, Economics and Finance, College of Law and Management Studies, University of KwaZulu-Natal, Durban, South Africa, ${ }^{5}$ Health, Nutrition and Population (HNP) Global Practice, The World Bank (Bangladesh), Dhaka, Bangladesh, ${ }^{6}$ NHMRC Clinical Trials Centre, University of Sydney, Sydney, QLD, Australia, ${ }^{7}$ Centre for Health Research, University of Southern Queensland, Queensland, QLD, Australia
\end{abstract}

Objectives: The main objectives of this study were to examine the prevalence of workplace violence (WPV), its associated factors and explore the experiences of healthcare workers.

Methods: A hospital-based cross-sectional study design used a nationally representative sample of 1,081 healthcare workers covering eight administrative divisions of Bangladesh. Logistic regression analysis was employed to estimate the adjusted effect of independent factors on WPV among healthcare workers.

Edited by:

Nino Kuenzli, Swiss Tropical and Public Health Institute (Swiss TPH), Switzerland

Reviewed by: Andrew Gibbs, South African Medical Research Council, South Africa Jihene Sahli, University of Sousse, Tunisia

*Correspondence: Md. Shahjalal md.shahjalal3@northsouth.edu

This Original Article is part of the IJPH Special Issue "Health in All Sustainable Development Goals"

Received: 09 August 2021 Accepted: 10 December 2021 Published: 31 December 2021

Citation:

Shahjalal M, Gow J, Alam MM, Ahmed T, Chakma SK, Mohsin FM, Hawlader MDH and Mahumud RA (2021) Workplace Violence Among Health Care Professionals in Public and Private Health Facilities in Bangladesh. Int J Public Health 66:1604396. doi: 10.3389/ijph.2021.1604396
Results: Of the participants, 43\% (468) experienced some form of WPV. Of those, 84\% reported experiencing nonphysical violence, and $16 \%$ experienced physical violence in the past year. About $65 \%$ of victims claimed no action was taken to investigate the incident, and 44\% reported no consequence for perpetrators. Four factors: being married ( $A O R=$ 1.63; Cl: 1.12-2.39); public sector healthcare worker (AOR = 2.74; Cl:1.99-3.76); working in an emergency department ( $A O R=2.30 ; \mathrm{Cl}: 1.03-5.12)$; and undertaking shift work (AOR $=1.52 ; \mathrm{Cl}: 1.10-2.11)$ were found to be significantly associated with WPV. One-third of the participants were worried about violence in their workplace.

Conclusion: WPV is highly prevalent among healthcare workers in Bangladesh. Formal guidelines for reporting and managing WPV are urgently needed at the individual, hospital, and national levels.

Keywords: healthcare workers, prevention, physical violence, non-physical violence, workplace of violence

\section{INTRODUCTION}

Workplace violence (WPV) encompasses both physical and nonphysical (verbal) violence. It is a growing public health concern among healthcare workers internationally, including in Bangladesh [1]. It is a key occupational hazard of healthcare workers. It is defined as any incident of a member of staff being abused, threatened, or assaulted on the grounds of their employment, including commuting to and from work, causing an implicit or explicit challenge to their safety, wellbeing, or health [2]. 
The World Health Organization (WHO) reported that violence in healthcare settings represents about a quarter of all violence in workplaces and that violence against healthcare workers is a global problem [3]. The WHO conducted a seven-country case study on WPV in the health sector and reported that more than 50\% of responding workers experienced at least one incident of either physical or nonphysical violence in the preceding year: $37 \%$ in Portugal, $46 \%$ in Brazil, $54 \%$ in Thailand, $61 \%$ in South Africa, $67 \%$ in Australia, and $75 \%$ in Bulgaria [3]. A recent systematic review documented that the 12-months prevalence of any form of WPV was $61 \%$ globally among healthcare workers [4]. About $42 \%$ experienced nonphysical violence, for example, verbal abuse (57\%), threats (32\%), sexual advances (12\%), while $24 \%$ reported physical violence. This review also indicated that $64 \%$ of Asian healthcare workers had experienced WPV: nonphysical $45 \%$ and physical $24 \%$ [4].

It is well known that violence occurs in all workplaces; however, healthcare workers are more prone to experience WPV than almost any other profession in both developed and developing countries [4,5]. The prevalence of WPV among healthcare workers is high in Asian countries: $51 \%$ in Pakistan [6], $62 \%$ in China [7], and $63 \%$ in India [8]. These studies also estimated that verbal or nonphysical violence was more prevalent than physical violence among healthcare workers. In Bangladesh, violence against healthcare workers is not a new issue. An analysis of media reports suggests that $96 \%$ of reported violence cases were physical, $91 \%$ occurred in public health care settings, and $52 \%$ occurred in emergency departments [9]. Unfortunately, healthcare services in Bangladesh are experiencing severe shortages of skilled healthcare workers $[10,11]$.

Many studies have shown that nurses are more vulnerable than doctors and other healthcare workers $[4,6,12]$ to WPV, while some studies found that doctors are most susceptible [8, 12]. Previous studies showed that a number of factors were associated with WPV in healthcare settings, including occupation, gender, age, marital status, healthcare level, healthcare sector, work schedule, and department $[1,2,4-6$, $8-10]$. Most researchers reported that doctors [1, 4, 6], being male $[4,7]$, and younger age $[2,13]$ health workers have a higher risk of experiencing WPV. Additionally, healthcare workers who worked in the emergency department $[1,9,10,13]$, public hospital $[1,6,9]$, tertiary healthcare facilities [1, 14], and shift work $[4,5,13]$ were positively associated with WPV.

WPV has been associated with post-traumatic stress disorder symptoms such as being "super alert" and watchful, feeling chronic fatigue or being bothered by repeated memories of the incident, low performance, absenteeism and staff turnover, lower productivity, and motivation as well as professional dissatisfaction, leading to decreased quality of care for patients $[3,4]$. WPV against healthcare workers has a devasting impact on victims' psychological and social well-being [1,4]. A significant portion of victims or those who witnessed WPV had some form of mental health consequence as a result. A recent study showed that around two-third of respondents had mental health problems after exposure to or witnessed violence [6]. After an episode of WPV, there are growing rates of missed workdays, burnout, job dissatisfaction, decreased productivity and ceasing employment [9, 13, 15]. In some cases of WPV, healthcare workers have protested to voice their opinion against offenders. This can lead to loss of workdays, reduced health services, and an increased burden on patients and the health care system $[9,13,15]$.

Most reports on WPV and healthcare workers have appeared in the media through newspapers and electronic media in Bangladesh but without systematic research as to the actual prevalence and effects of WPV [9].

Therefore, this study sought to examine the prevalence of WPV, its associated factors and explore the experiences of healthcare workers. The study also aimed to examine preventive strategies and provide suggestions to policymakers.

\section{METHODS}

\section{Study Design and Participants}

A hospital-based cross-sectional study of healthcare workers (doctors, nurses, others, e.g., midwives, laboratory technicians, administrative professionals) was conducted in primary, secondary, and tertiary level of healthcare settings, including public and private healthcare providers in eight administrative divisions of Bangladesh. The target population was healthcare workers who had patient contact. Personnel who met any of the following criteria were excluded: less than 1 year of work experience in the hospital, interns and trainees. Data were collected from November 2019 to March 2020.

\section{Survey Procedures}

Sampling was stratified by healthcare facility type at the political administration level. Specifically, primary care facilities provide healthcare at the sub-district level (Upazilla health complex and below); secondary healthcare settings are usually located at the district level, while tertiary healthcare settings consist of medical colleges, specialist hospitals, and national hospitals, healthcare institutes, etc. Convenient sampling of primary, secondary and tertiary healthcare facilities across eight divisions in both public and private sectors was undertaken.

A structured questionnaire was used to collect sociodemographic information, healthcare settings, healthcare sectors, details of violence experienced in the past 12 months, problems and impacts encountered by the violent episode, and preventive measures. Healthcare workers on duty were invited to complete the questionnaire, and these included doctors, nurses, midwives, and laboratory technicians who had patient contact in their daily practices. Before conducting the survey, the study objectives, aims, methods, and benefits of this study were explained, and participants gave their written approval or not before proceeding.

The questionnaire was based on the WHO instrumental survey tool, previously used in Australia, South Africa, Portugal, Bulgaria, and Thailand [12]. In this study, that questionnaire was slightly adapted. The questionnaire comprised three sections [1]: Socio-demographic information and professional background [2]; Experience 
Table 1 | Participants' demographic and professional characteristics, Bangladesh, 2020.

Participant characteristics

Profession

Doctors

Nurses

Other healthcare workers

Gender

Male

Female

Age

$<35$ years

35-44 years

$>44$ years

Marital status

Married

Unmarried

Level of healthcare setting

Primary

Secondary

Tertiary

Type of healthcare sector

Public

Private

Years of experience

$<6$ years

6-10 years

11-15 years

16-20 years

$>20$ years

Working department

General medicine

General surgery

Emergency

Intensive care

Pediatrics

Gynecology and obstetrics

Orthopedics

ENT (eye, nose and tongue)

Management

Other departments

Rotating shift work

Yes

No

Workplace location

Dhaka division

Chittagong division

Sylhet division

Khulna division

Rangpur division

Barisal division

Rajshahi division

Mymensingh division
Number

of participants (n)

Percentage of participants (\%)

692

285

104

516

565

773

261

47

651

430

168

127

786

602

479

664

211

121

44

41

148

148
149

169

54

88

95

49

30

36

263

521

560

258

144

100

120

137

98

123

101

64.01

26.36

9.62

47.73

52.27

71.50

24.14

4.34

60.22

39.78

15.54

11.75

72.71

55.69

44.31

61.42

19.51

11.20

4.07

3.79

13.69

13.78

15.63

5.00

8.14

8.79

4.53

2.78

3.33

24.33

48.20

51.80

23.86

13.32

9.25

11.10

12.67

9.06

11.37

9.34 of WPV in the last 12 months, types and the number of instances, rehabilitation assistance to victims and their satisfaction with the assistance, reasons for underreporting or not reporting violence, and victim responses to and consequences for perpetrators [3]; Participant witnessing of violence in the previous year, anxiety and knowledge of WPV and preventive strategies. After voluntary consenting to participate, each respondent completed an anonymous questionnaire and returned it to the data collector. Respondents' names and addresses were not required. Based on this procedure, 1,081 valid responses were collected (78.3\% correct response rate). 


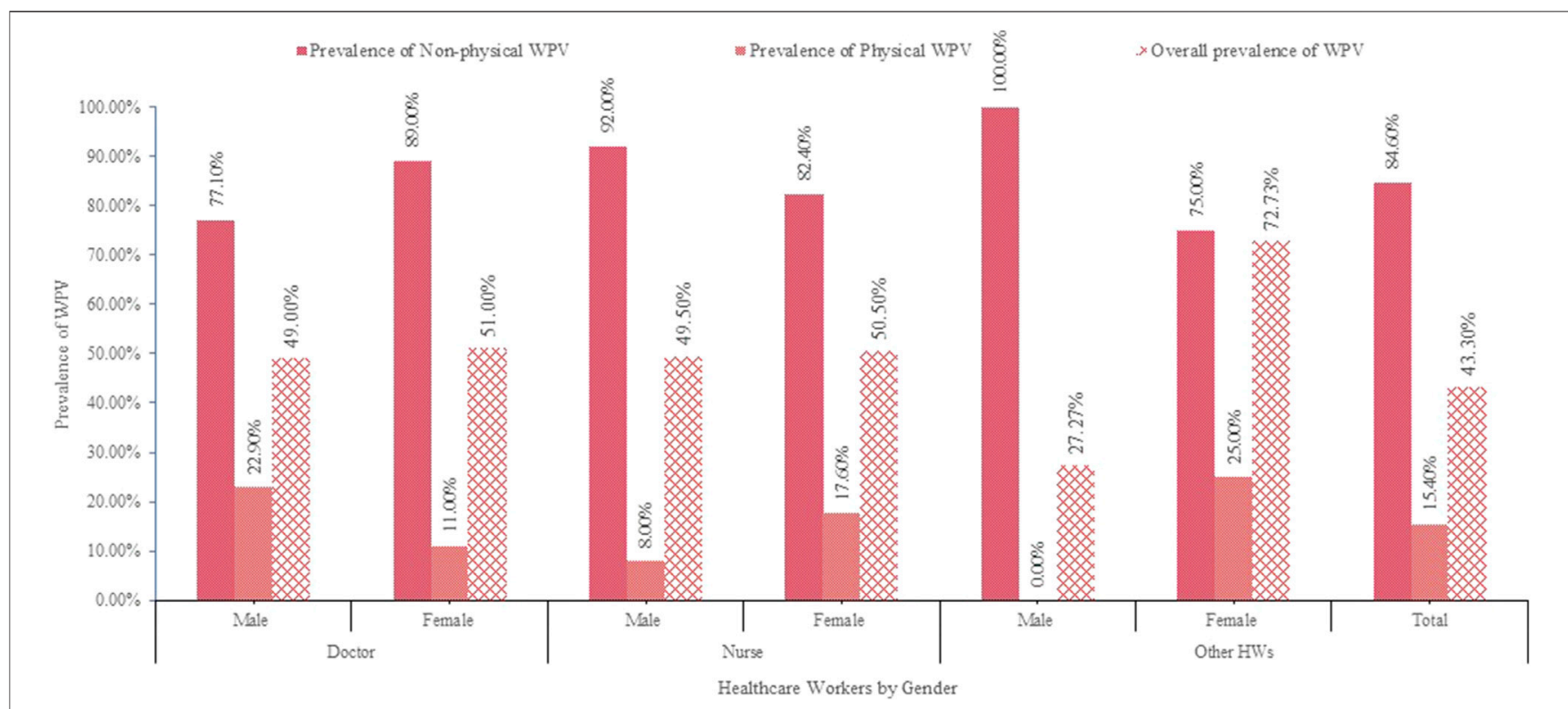

FIGURE 1 | Prevalence of workplace violence (WPV) among healthcare workers, Bangladesh, 2020.

\section{Operational Definition}

Physical violence was defined as the application of force or action, including pinching, pushing, shoving, and spitting or kicking, with or without the use of weapons, as well as rape [3].

Non-physical violence was defined as verbal abuse, threats, bullying/mobbing, frightening action(s), and unwanted sexual advances [3].

\section{Statistical Analysis}

We calculated descriptive statistics for demographic characteristics and frequency of exposure to WPV. Frequency distributions were calculated (in percentage points) for physical and nonphysical violence experienced by personnel in each professional category. In the analytical exploration, binary logistic regression analysis was used to determine which demographic and professional characteristics (including gender, marital status, age, experience, profession, department, shift work involved) associated experiencing physical or nonphysical violence. Based on only separated explanatory variables, an unadjusted regression analysis was performed. In the final model (adjusted), potential explanatory variables were only considered if any label of the covariate was statistically significant with a $p$-value at $5 \%$ or less in the unadjusted model. Statistical analyses were performed with SPSS v.25.

\section{RESULTS}

\section{Demographic and Professional Characteristics of the Respondents}

A total of 1,081 healthcare workers participated in this study from all regions of Bangladesh (Table 1). The mean age of participants was 30.83 years (SD: $6.75 ; \min : 20$, max:67). The majority of participants were doctors $(64.0 \%)$, female $(52.3 \%)$, $<35$ years of age $(71.5 \%)$ and married $(60.2 \%)$. Over half of the participants had experienced less than 6 years $(61.4 \%)$, worked in tertiary healthcare settings $(72.7 \%)$, for the public health sector $(55.0 \%)$, and in fixed shift $(51.8 \%)$. The spatial distribution of respondents was even across the nation.

The prevalence of WPV varies by gender and profession (Figure 1). Overall, 468 (43.3\%) incidents were reported, with $84.6 \%$ nonphysical and $15.4 \%$ physical. About $51.4 \%$ of doctors and $35.4 \%$ of nurses had exposure to some form of violence. Physicians were the most vulnerable to physical violence, while nurses were the most susceptible to nonphysical violence.

\section{Associations Between Violence Exposure and Respondents' Characteristics}

Table 2 shows the outcome of the multiple logistic regression model, which was used to assess the predictive factors for WPV. It was found to be significantly associated with profession, marital status, health care sector, specialized department, and shift work $(p<0.05)$.

Compared to nurses, violence among doctors was higher (51.4\%). The prevalence of WPV was significantly lower among other healthcare workers (AOR $=0.27$; CI: 0.11-0.67). Participants who were married experienced a higher prevalence of WPV compared to those never married $(\mathrm{AOR}=1.63$; $\mathrm{CI}$ : 1.11-2.38). Participants from the public sector experienced 2.73 times higher WPV than their private-sector colleagues $(\mathrm{AOR}=2.73$; CI: 1.99-3.76).

Healthcare workers in emergency departments $(\mathrm{AOR}=2.30$; CI: 1.03-5.12) were more likely to have experienced WPV than 
Table 2 | Multivariate adjusted and unadjusted odds for respondents' exposure to violence, Bangladesh, 2020.

\begin{tabular}{|c|c|c|c|c|c|}
\hline \multirow[t]{2}{*}{ Participant characteristics } & \multirow[t]{2}{*}{ Prevalence of WPV } & \multicolumn{2}{|c|}{ Unadjusted model } & \multicolumn{2}{|c|}{ Adjusted model } \\
\hline & & OR & $95 \% \mathrm{Cl}$ & AOR & $95 \% \mathrm{Cl}$ \\
\hline \multicolumn{6}{|l|}{ Profession } \\
\hline Doctor & $356(51.4)$ & 1.93 & $1.45-2.56$ & 0.98 & $0.67-1.41$ \\
\hline Nurse (=ref) & $101(35.4)$ & 1.00 & 1.00 & 1.00 & 1.00 \\
\hline Other health workers & $11(10.6)$ & 0.21 & $0.11-0.42$ & 0.27 & $0.11-0.67$ \\
\hline \multicolumn{6}{|l|}{ Gender } \\
\hline Female & 235 (42.6) & 0.93 & $0.73-1.18$ & 0.99 & $0.74-1.33$ \\
\hline Male (=ref) & $233(44.0)$ & 1.00 & 1.00 & 1.00 & 1.00 \\
\hline \multicolumn{6}{|l|}{ Age } \\
\hline$<35$ years & $274(35.4)$ & 0.34 & $0.18-0.62$ & 0.94 & $0.16-5.39$ \\
\hline 35-44 years & $165(63.2)$ & 1.07 & $0.56-2.02$ & 1.33 & $0.26-6.84$ \\
\hline$>44$ years $(=r e f)$ & $29(61.7)$ & 1.00 & 1.00 & 1.00 & 1.00 \\
\hline \multicolumn{6}{|l|}{ Marital status } \\
\hline Married & $331(50.8)$ & 2.21 & $1.71-2.85$ & 1.63 & $1.12-2.39$ \\
\hline Unmarried (=ref) & $137(31.9)$ & 1.00 & 1.00 & 1.00 & 1.00 \\
\hline \multicolumn{6}{|l|}{ Healthcare setting } \\
\hline Primary & $55(32.7)$ & 0.59 & $0.42-0.84$ & 0.84 & $0.50-1.39$ \\
\hline Secondary & $59(46.5)$ & 1.06 & $0.73-1.54$ & 0.96 & $0.60-1.53$ \\
\hline Tertiary (=ref) & $354(45.0)$ & 1.00 & 1.00 & 1.00 & 1.00 \\
\hline \multicolumn{6}{|l|}{ Healthcare sector } \\
\hline Public & $325(54.0)$ & 2.75 & $2.14-3.55$ & 2.74 & $1.99-3.76$ \\
\hline Private & $143(29.9)$ & 1.00 & 1.00 & 1.00 & 1.00 \\
\hline \multicolumn{6}{|l|}{ Years of experience } \\
\hline$<6$ years & 205 (30.9) & 0.26 & $0.13-0.49$ & 0.50 & $0.08-3.23$ \\
\hline $6-10$ years & $124(58.8)$ & 0.82 & $0.41-1.64$ & 0.84 & $0.14-5.15$ \\
\hline $11-15$ years & $86(71.1)$ & 1.42 & $0.67-2.99$ & 1.06 & $0.17-6.50$ \\
\hline 16-20 years & $27(61.4)$ & 0.91 & $0.38-2.20$ & 0.62 & $0.12-3.08$ \\
\hline >20 years (=ref) & $26(63.4)$ & 1.00 & 1.00 & 1.00 & 1.00 \\
\hline \multicolumn{6}{|l|}{ Working department } \\
\hline General medicine & $60(40.5)$ & 0.61 & $0.29-1.26$ & 0.64 & $0.29-1.41$ \\
\hline General surgery & $76(51.0)$ & 0.93 & $0.45-1.93$ & 1.22 & $0.55-2.74$ \\
\hline Emergency & $123(72.8)$ & 2.39 & $1.14-4.99$ & 2.30 & $1.03-5.12$ \\
\hline Intensive care & $26(48.1)$ & 0.83 & $0.35-1.93$ & 0.85 & $0.33-2.15$ \\
\hline Pediatrics & $42(47.7)$ & 0.82 & $0.37-1.77$ & 0.78 & $0.34-1.80$ \\
\hline Gyne and obstetrics & 37 (38.9) & 0.57 & $0.26-1.23$ & 0.56 & $0.24-1.30$ \\
\hline Orthopedics & $22(44.9)$ & 0.73 & $0.30-1.72$ & 0.59 & $0.22-1.48$ \\
\hline E.N.T. department & $14(46.7)$ & 0.78 & $0.29-2.06$ & 0.76 & $0.26-1.98$ \\
\hline Other departments & 49 (18.6) & 0.20 & $0.09-0.42$ & 0.37 & $0.17-0.79$ \\
\hline Management (=ref) & $19(52.8)$ & 1.00 & 1.00 & 1.00 & 1.00 \\
\hline \multicolumn{6}{|l|}{ Rotating shift work } \\
\hline Yes & $290(55.7)$ & 2.69 & $(2.10-3.45)$ & 1.52 & $1.10-2.11$ \\
\hline No (=ref) & 178 (31.8) & 1.00 & 1.00 & 1.00 & 1.00 \\
\hline \multicolumn{4}{|c|}{ Hosmer-Lesmeshow statistics ( $p$ value) } & 17.42 & \\
\hline
\end{tabular}

those who worked in other departments. WPV was also higher among healthcare workers who were shift workers $(\mathrm{AOR}=1.52$; CI: $1.10-2.11)$.

\section{Perpetrators and Consequences}

Regarding perpetrators, family members or relatives of the patients were the main perpetrators $(73.1 \%)$, while $29.1 \%$ of cases involved the patient. Approximately $14.3 \%$ of victims reported being injured due to violence, while $22.4 \%$ had to leave work after being subjected to violence. Approximately $65 \%$ of victims claimed no action was taken to investigate the incident and $44.0 \%$ reported no consequences for the perpetrator(s) (Table 3).

\section{Reactions of Victims and Underreporting of WPV}

Most of the victims (72.6\%) stated that they did not react to the incident, while $60.3 \%$ believed it could have been prevented. Most victims (79.9\%) claimed that their employer did nothing when the violence was reported to them, and $79.7 \%$ were not satisfied with the manner in which the situation was handled (Table 3). 
Table 3 | Distribution of study participants exposed to workplace violence, Bangladesh, 2020.

\begin{tabular}{|c|c|c|}
\hline Variables & Number & Percentage \\
\hline \multicolumn{3}{|l|}{ Perpetrators } \\
\hline Patient & 136 & 29.10 \\
\hline Relatives of the patient & 342 & 73.10 \\
\hline Staff member & 27 & 5.80 \\
\hline Supervisor or management & 44 & 9.40 \\
\hline General Public & 54 & 11.50 \\
\hline \multicolumn{3}{|l|}{ Injuries caused by violence } \\
\hline Yes & 67 & 14.30 \\
\hline No & 401 & 85.70 \\
\hline \multicolumn{3}{|c|}{ After being a victim, take time off from work } \\
\hline Yes & 105 & 22.40 \\
\hline No & 363 & 77.60 \\
\hline \multicolumn{3}{|c|}{ Action was taken to investigate the incident } \\
\hline Yes & 81 & 17.30 \\
\hline No & 306 & 65.40 \\
\hline Don't know & 81 & 17.30 \\
\hline \multicolumn{3}{|l|}{ Consequences for the perpetrator } \\
\hline None & 206 & 44.00 \\
\hline Verbal warning & 79 & 16.90 \\
\hline Care discontinued & 16 & 3.40 \\
\hline Reported to police & 16 & 3.40 \\
\hline Aggressor prosecuted & 9 & 1.90 \\
\hline Do not know & 142 & 30.30 \\
\hline \multicolumn{3}{|l|}{ Victims respond to the incident } \\
\hline Yes & 128 & 27.40 \\
\hline No & 340 & 72.60 \\
\hline \multicolumn{3}{|l|}{ Incident was preventable } \\
\hline Yes & 282 & 60.30 \\
\hline No & 186 & 39.70 \\
\hline \multicolumn{3}{|l|}{ Supports from employer } \\
\hline Yes & 94 & 20.10 \\
\hline No & 374 & 79.90 \\
\hline \multicolumn{3}{|c|}{ Satisfaction with the way the situation was handled } \\
\hline Yes & 95 & 20.30 \\
\hline No & 373 & 79.70 \\
\hline \multicolumn{3}{|c|}{ Reason for not reporting or talking about the incident } \\
\hline It was not important & 68 & 14.50 \\
\hline Felt ashamed & 50 & 10.70 \\
\hline Felt guilty & 22 & 4.70 \\
\hline Afraid of negative consequence & 88 & 18.80 \\
\hline Fear of being fire from job & 58 & 12.40 \\
\hline Did not know who to report & 77 & 16.50 \\
\hline Others & 105 & 22.40 \\
\hline \multicolumn{3}{|c|}{ Worried about violence in the current workplace } \\
\hline Not worried at all & 265 & 24.5 \\
\hline A little & 300 & 27.8 \\
\hline Worried & 244 & 22.6 \\
\hline Very worried & 272 & 25.2 \\
\hline \multicolumn{3}{|c|}{ Procedures for the reporting of violence in the workplace } \\
\hline Yes & 422 & 39.0 \\
\hline No & 265 & 24.5 \\
\hline Don't know & 394 & 36.4 \\
\hline \multicolumn{3}{|c|}{ Participated in any violence prevention training program } \\
\hline Yes & 251 & 23.2 \\
\hline No & 830 & 76.8 \\
\hline
\end{tabular}

Table 3 | (Continued) Distribution of study participants exposed to workplace violence, Bangladesh, 2020.

\begin{tabular}{lcc}
\hline Variables & Number & Percentage \\
\hline Existing WPV prevention and control policies in the workplace & \\
Yes & 118 & 10.9 \\
No & 382 & 35.3 \\
Don't know & 581 & 53.7 \\
\hline
\end{tabular}

WPV victims disclosed various types of reasons for not reporting incidents to the authorities. About $14.5 \%$ of victims thought it was unimportant, $16.5 \%$ said they did not know whom to report to, $18.8 \%$ were afraid of negative consequences, $10.7 \%$ felt ashamed, and $12.4 \%$ were afraid of being fired from their job. About $24.4 \%$ of participants were not worried about violence in their current workplace, while $27.8 \%$ were a little worried, $22.6 \%$ were worried, and $25.2 \%$ were very worried (Table 3).

Knowledge of preventive strategies and suggestions to prevent WPV About $24.5 \%$ of victims claimed no procedures for reporting the violent incidences, and $36.4 \%$ stated they had no idea about the process for reporting violence at their workplace. Participants were asked about any training or workshops on WPV they had undertaken, and $76.8 \%$ replied that they had not taken part in any training or workshop to deal with WPV. Over half of respondents (53.7\%) stated no existing WPV prevention and control policies in their workplace (Table 3).

Participants were also asked about measures that could be taken to prevent violence. All participants could mark more than one choice. Measures that could be taken to avoid the violence include security measures $67.2 \%$ (727), improving surroundings $59.4 \%$ (642), increased staff members $52.2 \%$ (565), and patient protocol $50.3 \%(544)$. They also suggested that training programs, reduced time working alone, shift changes, restricting public access, and restricting money exchange in hospitals could also be effective (Figure 2).

\section{DISCUSSION}

This study investigated workplace violence experiences among healthcare workers (doctors, nurses, midwives, medical technologists, administrative staff) in Bangladesh and its characteristics. The analysis revealed the overall prevalence of WPV and differences in prevalence among various categories of healthcare workers. Moreover, the distribution of physical and nonphysical violence, associated factors, and potential preventive strategies was analyzed.

This study obtained a $43.3 \%$ prevalence of WPV among healthcare workers, of which $84.6 \%$ were non-physical, and the remaining $15.4 \%$ was physical. The prevalence is lower than a study conducted in China (49.2\%) [17] but higher than in India (40.8\%) [18]. A Turkish study of doctors identified a very high $78.1 \%$ prevalence of WPV in the emergency department [16]. The current study has also revealed that respondents from 


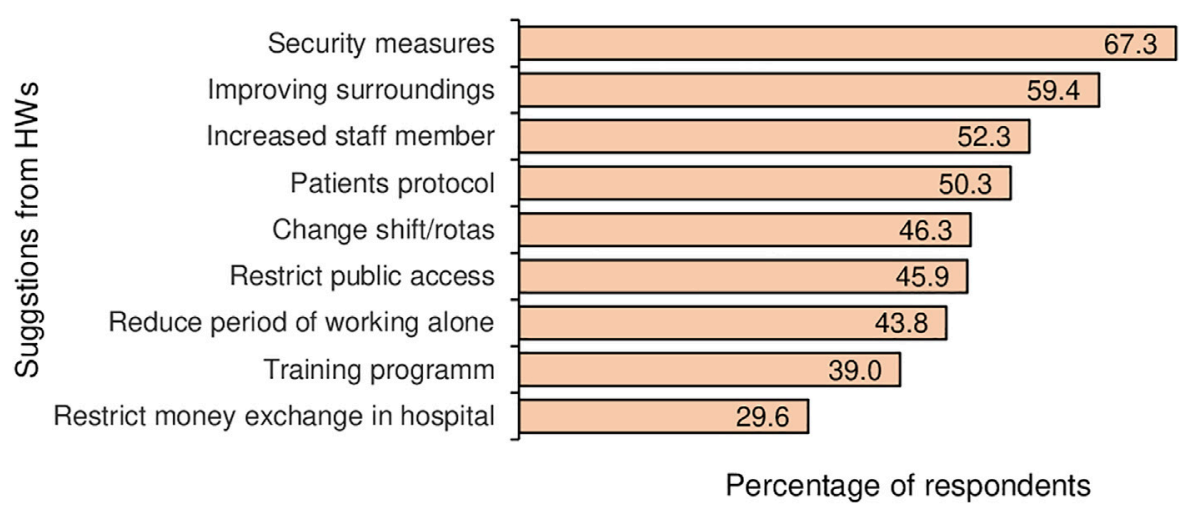

FIGURE 2 | Suggestions from healthcare workers (HW) to prevent workplace violence (multiple responses), Bangladesh, 2020.

the emergency department $(72.8 \%)$, followed by management $(52.8 \%)$ and general surgery $(51 \%)$, were more likely to have experienced violence than those who worked in other departments. There have been increasing workplace violence trends, as previously reported that in Bangladesh, 91\% of violence took place in public healthcare settings [9]. Studies conducted worldwide identified quite diverse prevalence rates among the various types of health care professionals and at multiple levels (primary, secondary, tertiary) [14, 19, 20]. In this study, a higher prevalence of WPV among doctors compared to nurses was observed. However, WPV was very low $(10.6 \%)$ among other healthcare workers. The prevalence was also relatively low in primary health care settings compared to secondary and tertiary levels.

Doctors in an emergency, psychiatrists, and those involved with primary care are at increased risk of violent acts from patients and families. Emergency departments, intensive care units, and post-surgical wards are the most common settings for violence $[19,20]$. Working in an emergency department with a high patient admission rate increases the probability of experiencing WPV [16]. There were statistically significant differences in the experience of violence who worked at public and private hospitals. A study conducted in Palestine showed a tendency for those who worked in public hospitals to be more likely to experience violence [21]. Further, respondents who were shift workers were four times more likely to have experienced violence than those who did not work shifts [22].

There are often difficulties with relations between healthcare workers and their patients in Bangladesh, as multiple newspaper reports collated and published recently can attest [23]. Most perpetrators of violence were relatives of the patient. An Indian study also identified similar findings as perpetrators were visitors/relatives $(48 \%)$, patients $(38 \%)$, and co-workers (14\%) [21].

Non-reporting of violence is a concerning issue, mainly due to the lack of policy or procedure and management support, having previous experience of no action taken, and fear of the consequences. The results identified not knowing whom to report to as the main reason behind non-reporting. The majority of the victims took no action to investigate the incidents, and $36.6 \%$ had no idea about the consequences for the perpetrator(s).

The study results confirm that among the suggested measures, security measures were the most commonly implemented. However, these measures were reactive rather than proactive and tackled a particular risk (physical violence) rather than WPV as a whole. In light of international and national experiences, it is only with comprehensive preventive measures and penalties that actions against WPV at hospitals can be practical.

As outlined in the international labor organization (ILO) convention (No. 190) and recommendation (No. 206), "Governments should adopt legislation requiring employers to secure adequate protection against workplace violence and harassment." [24]. However, no national guidelines in Bangladesh ensure employers' legal responsibility to provide a safe, decent and healthy working environment for employees, where protection of their legitimate rights is enforced. The interests of health workers and, in particular, their safety is not being prioritized by specific government legislation.

The outlined WPV preventive measures are widely accepted as comprehensive measures to address workplace the risk factors of WPV. Therefore, the following are suggestions for wide measures to combat WPV in hospitals in Bangladesh. First, create a positive culture to combat violence. To create a harmonious doctor-patient relationship, respect, tolerance, gender sensitivity, equality, collaboration, and care should be practiced, and no form of WPV should be tolerated. Second, organizational interventions should be conducted whereby hospitals need to invest in human resource development. Improving staff or patient rations to reduce staff shortages will minimize time pressure on health workers. Effective organization of workloads can reduce the number of consecutive night shifts and the long working hours experienced.

Third, implement interventions to optimize service delivery to reduce waiting times, design comfortable and convenient waiting areas, and design escape doors for highrisk departments (such as emergency) staff. It is crucial to limiting public access, including security checks on visitors, 
and provide safe areas for staff (such as changing rooms). Fourth, hospitals should be required to provide victims with medical treatment, psychological counseling, and financial compensation, while perpetrators should be punished under the law. Fifth, develop and introduce practical measures for prevention and control, such as measuring the prevalence of violence, the impact of violence, and undertaking risk assessments.

\section{Strengths and Limitations}

This survey is the first comprehensive study of WPV against healthcare workers and revealed the WPV situation in healthcare settings in Bangladesh. In this study, relatively a large sample size was obtained, considering the total number of healthcare workers in Bangladesh. The study results can contribute to developing appropriate policy and strategies on WPV against healthcare workers and serve as the basis for future research in the country.

This study has several limitations. First, this study was completed in response to an open invitation; thus, it might have been completed mainly by healthcare workers who had been subjected to violence in the past and therefore are more sensitive to this issue. Data were collected retrospectively; these methods rely on the respondents' ability to recall events in the past year, which could result in recall bias. Second, a convenience sampling design was used in this study, so the results cannot be generalized. Finally, the survey was not tested and validated before this study.

\section{Conclusion}

This study has outlined the prevalence of WPV among healthcare workers in Bangladesh, and the results indicate that these healthcare workers are vulnerable to WPV. Several potential associated factors of WPV, such as profession, marital status, healthcare sector, specialized department, and shift work was observed. Some critical factors, such as the reluctant attitudes of employers and employees regarding WPV, which include underreporting by employees, lack of knowledge among healthcare workers, low job security, and inefficient action by authorities, are some of the primary reasons behind the burden of WPV. Considering our findings, this issue cannot be ignored, especially from the point of view of occupational health and

\section{REFERENCES}

1. Ma J, Chen X, Zheng Q, Zhang Y, Ming Z, Wang D, et al. Serious Workplace Violence against Healthcare Providers in China between 2004 and 2018. Front Public Health (2021) 8:574765. doi:10.3389/fpubh.2020.574765

2. Kobayashi Y, Oe M, Ishida T, Matsuoka M, Chiba H, Uchimura N. Workplace Violence and its Effects on Burnout and Secondary Traumatic Stress Among Mental Healthcare Nurses in Japan. Int J Environ Res Public Health (2020) 17(8):2747. doi:10.3390/ijerph17082747

3. Di Martineo V. Workplace Violence in the Health Sector Country Case Studies Brazil, Bulgaria, Lebanon, Portugal, South Africa, Thailand and an Additional Australian Study. Synth Rep (2009) 2009:1-49. Available from: https://www. who.int/violence_injury_prevention/violence/activities/workplace/WVsynthesisreport. pdf?ua=1 (Accessed August 8, 2021). safety. To reduce WPV and create safe working environments, we recommend developing preventive safety policies, procedures, and prevention training. Further research is needed to understand how to reduce WPV against healthcare workers.

\section{ETHICS STATEMENT}

The studies involving human participants were reviewed and approved by Institutional Review Board (IRB) at North South University, Dhaka-1229, Bangladesh (2020/OR-NSU/IRBNo.0801). The participants provided their written informed consent to participate in this study. Written informed consent was obtained from the individual(s) for the publication of any potentially identifiable images or data included in this article.

\section{AUTHOR CONTRIBUTIONS}

Conceptualized the study: MS; Contributed data extraction and analyses: MS under the guidance of RAM. Result interpretation: MS under the guidance of RAM. Prepared the first draft: MS, JG, MMA, TA and RAM. Contributed during the conceptualization and interpretation of results and substantial revision: MS, JG, MMA, MDHH, TA, SKC, FMM, and RAM. Revised and finalized the final manuscript: MS, JG, MMA, MDHH, TA, SKC, FMM, and RAM. All authors read and approved the final version of the manuscript.

\section{CONFLICT OF INTEREST}

The authors declare that the research was conducted in the absence of any commercial or financial relationships that could be construed as a potential conflict of interest.

\section{ACKNOWLEDGMENTS}

We would like to thank everyone who took part in this survey. We also want to thank the data collectors and hospital authorities for their assistance.

4. Liu J, Gan Y, Jiang H, Li L, Dwyer R, Lu K, et al. Prevalence of Workplace Violence against Healthcare Workers: A Systematic Review and Meta-Analysis. Occup Environ Med (2019) 76:927-37. doi:10.1136/oemed-2019-105849

5. Needham I, Mckenna K. Workplace Violence in the Health Sector. Proc First Int Conf Work Violence Heal Sect - Together, Create a Safe Work Environ (2008). p. 383. Available from: http://www.mtpinnacle.com/pdfs/Boek_Workplace_ Violence.pdf (Accessed August 8, 2021).

6. Khan MN, Haq ZU, Khan M, Wali S, Baddia F, Rasul S, et al. Prevalence and Determinants of Violence against Health Care in the Metropolitan City of Peshawar: a Cross Sectional Study. BMC Public Health (2021) 21(1):330. doi:10.1186/s12889-021-10243-8

7. Lu L, Dong M, Wang S-B, Zhang L, Ng CH, Ungvari GS, et al. Prevalence of Workplace Violence against Health-Care Professionals in China: A Comprehensive Meta-Analysis of Observational Surveys. Trauma, Violence, \& Abuse (2020) 21(3):498-509. doi:10.1177/1524838018774429 
8. Hossain MM, Sharma R, Tasnim S, Al Kibria GM, Sultana A, Saxena T. Prevalence, Characteristics, and Associated Factors of Workplace Violence against Healthcare Professionals in India: A Systematic Review and MetaAnalysis. Evid Based Psychosocial Health (2020). doi:10.1101/2020.01.01.20016295

9. Hasan MI, Hassan MZ, Bulbul MMI, Joarder T, Chisti MJ. Iceberg of Workplace Violence in Health Sector of Bangladesh. BMC Res Notes (2018) 11(1):702. doi:10.1186/s13104-018-3795-6

10. Hossain R. Current Status of Health Sector in Bangladesh. Bangladesh Med J (2016) 44(1):46-50. doi:10.3329/bmj.v44i1.26356

11. Global Health Workforce Alliance. Health Workers for All and All for Health Workers: An Agenda for Global Action (2008). p. 1-8. Available from: https:// www.who.int/workforcealliance/countries/bgd/en/(Accessed August 8, 2021).

12. Di Martino V. Country Case Studies: Brazil, Bulgaria, Lebanon, Portugal, South Africa, Thailand and an Additional Australian Study (2002). Available from: https://www.who.int/violence_injury_prevention/violence/activities/ workplace/WVsynthesisreport.pdf?ua=1 (Accessed August 8, 2021).

13. Kumari A, Kaur T, Ranjan P, Chopra S, Sarkar S, Baitha U. Workplace Violence against Doctors: Characteristics, Risk Factors, and Mitigation Strategies. J Postgrad Med (2020) 66(3):149-54. doi:10.4103/jpgm.JPGM_96_20

14. Li Y-L, Li R-Q, Qiu D, Xiao S-Y. Prevalence of Workplace Physical Violence against Health Care Professionals by Patients and Visitors: A Systematic Review and Meta-Analysis. Int J Environ Res Public Health (2020) 17(1): 299. doi:10.3390/IJERPH17010299

15. Sun T, Gao L, Li F, Shi Y, Xie F, Wang J, et al. Workplace Violence, Psychological Stress, Sleep Quality and Subjective Health in Chinese Doctors: a Large Cross-Sectional Study. BMJ Open (2017) 7(12):e017182. doi:10.1136/bmjopen-2017-017182

16. Bayram B, Çetin M, Çolak Oray N, Can İÖ. Workplace Violence against Physicians in Turkey's Emergency Departments: a Cross-Sectional Survey. BMJ Open (2017) 7(6):e013568. doi:10.1136/bmjopen-2016-013568

17. Jia H, Fang H, Chen R, Jiao M, Wei L, Zhang G, et al. Workplace Violence against Healthcare Professionals in a Multiethnic Area: a Cross-Sectional
Study in Southwest China. BMJ Open (2020) 10(9):e037464. doi:10.1136/ bmjopen-2020-037464

18. Lindquist B, Koval K, Mahadevan A, Gennosa C, Leggio W, Niknam K, et al. Workplace Violence Among Prehospital Care Providers in India: A Cross-Sectional Study. BMJ Open (2019) 9(11):e033404. doi:10.1136/bmjopen-2019-033404

19. Vento S, Cainelli F, Vallone A. Violence against Healthcare Workers: A Worldwide Phenomenon with Serious Consequences. Front Public Health (2020) 8:541. doi:10.3389/FPUBH.2020.570459

20. Tian Y, Yue Y, Wang J, Luo T, Li Y, Zhou J. Workplace Violence against Hospital Healthcare Workers in China: a National WeChat-Based Survey. BMC Public Health (2020) 20(1):1-8. doi:10.1186/S12889-020-08708-3

21. Kitaneh M, Hamdan M. Workplace Violence against Physicians and Nurses in Palestinian Public Hospitals: a Cross-Sectional Study. BMC Health Serv Res (2012) 12(1):1-9. doi:10.1186/1472-6963-12-469

22. Campbell JC, Messing JT, Kub J, Agnew J, Fitzgerald S, Fowler B, et al. Workplace Violence. J Occup Environ Med (2011) 53(1):82-9. doi:10.1097/ JOM.0b013e3182028d55

23. Hasan MI, Hassan MZ, Bulbul MMI, Joarder T, Chisti MJ. Iceberg of Workplace Violence in Health Sector of Bangladesh. BMC Res Notes (2018) 11(1):1-6. doi:10.1186/s13104-018-3795-6

24. International Labour Organization. New International Labour Standard to Combat Violence, Harassment, at Work Agreed (2019). Available from: https:// www.ilo.org/ilc/ILCSessions/108/media-centre/news/WCMS_711321/langen/index.htm (Accessed August 8, 2021).

Copyright (c) 2021 Shahjalal, Gow, Alam, Ahmed, Chakma, Mohsin, Hawlader and Mahumud. This is an open-access article distributed under the terms of the Creative Commons Attribution License (CC BY). The use, distribution or reproduction in other forums is permitted, provided the original author(s) and the copyright owner(s) are credited and that the original publication in this journal is cited, in accordance with accepted academic practice. No use, distribution or reproduction is permitted which does not comply with these terms. 